\title{
A CRIATURA, A CRIADORA E A CRÍTICA: FRANKENSTEIN, DE MARY SHELLEY, SOB A ÓTICA DE UM TETO TODO SEU, DE VIRGINIA WOOLF
}

\author{
CREATURE, CREATOR AND CRITICISM: FRANKENSTEIN, BY \\ MARY SHELLEY, UNDER THE POINT OF VIEW OF A ROOM OF \\ ONE'S OWN, BY VIRGINIA WOOLF
}

\author{
Silvia Maria Fernandes Alves da Silva COSTA ${ }^{1}$ \\ Maria Aparecida Saraiva Magalhães de SOUSA ${ }^{2}$ \\ Luciana Eleonora de Freitas Calado DEPLAGNE ${ }^{3}$
}

\begin{abstract}
Resumo: Este artigo visa apresentar a autora inglesa Mary Shelley (1797-1851) como iniciadora da ficção científica com a obra Frankenstein ou o Prometeu Moderno (1818), e esta como uma obra matricial de autoria feminina, para questionar a sua possível ausência no Museu Britânico e/ou os valores canônicos defendidos por Virginia Woolf (1882-1941), a partir de seus apontamentos sobre a mulher na ficção, no ensaio Um teto todo seu (1929). Para isso, observaram-se os pontos críticos assinalados por Woolf, contrapostos com a vida de Mary Shelley e a obra Frankenstein, para se buscar entender a não referência a Shelley diante dos diversos nomes de autores citados no ensaio. Woolf admite que a estrutura patriarcal barrou a mulher, no decorrer dos séculos, em uma vida sem condições materiais para pensar e contemplar no momento da criação. Contudo, Shelley, mesmo vivendo em uma sociedade vitoriana patriarcal do século XIX, na qual a mulher deveria ser submissa ao homem, teve condições adequadas à produção ficcional ativa, escrevendo obras como Frankenstein, que permanece presente 200 anos após sua publicação, desafiando a todos com um magnetismo que perpassa o campo das artes. Uma obra que deveria estar incandescente nas estantes do Museu Britânico.
\end{abstract}

Palavras-chave: Mary Shelley. Frankenstein. Virginia Woolf. Autoria feminina. Um teto todo seu.

Abstract: This article aims to present English author Mary Shelley (1797-1851) as initiator of Science Fiction with the work Frankenstein or the Modern Prometheus (1818), and this as a matrix work of female authorship, to question its possible absence in the British Museum and/or the canonical values defended by Virginia Woolf (1882-1941), from her notes on woman in fiction, in her essay A room of one's own (1929). For that, the critical points pointed out by Woolf were observed and they were contrasted with the life of Mary Shelley and her work Frankenstein, in order to understand the nonreference to Shelley before the diverse authors names cited in the essay. Woolf admits that the patriarchal structure has barred women over the centuries in a life without material conditions to think and contemplate at the moment of creation. However, Shelley, even living in a nineteenth-century patriarchal Victorian society, in which women were supposed to be submissive to man, was fit enough for active fictional production, writing works such as Frankenstein, which remains present 200 years

\footnotetext{
${ }^{1}$ Doutoranda em Letras pela Universidade Federal da Paraíba. Professora de línguas estrangeiras (inglês e espanhol) do Instituto de Educação Antonino Freire, na Gerência de Formação de Professores da Educação Básica do Piauí. E-mail: <sf.costa@live.com>.

${ }^{2}$ Doutoranda em Letras pela Universidade Federal da Paraíba. Professora de português da Rede Estadual de Ensino da Paraíba. E-mail: <maria_asms@ @otmail.com>.

${ }^{3}$ Doutora em Letras pela Universidade Federal de Pernambuco. Professora Adjunto III do Departamento de Letras Clássicas e Vernáculas da UFPB. E-mail: <lucianaeleonora@yahoo.com.br>.
} 
after its publication, defying all with a magnetism that crosses the field of the arts. A work that should had been incandescent on the shelves of the British Museum.

Keywords: Mary Shelley. Frankenstein. Virginia Woolf. Female authorship. A room of one's own.

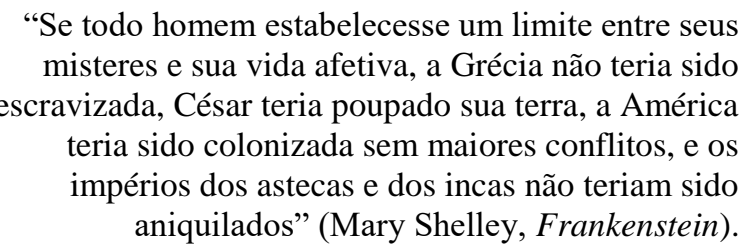

A relação entre a escrita das mulheres e a ficção tem trazido à tona diversos debates na atualidade. No contexto inglês, Virginia Woolf (1882-1941), no ensaio Um teto todo seu, publicado em 1929, apresenta a condição da mulher aprisionada pela estrutura patriarcal ao longo dos séculos, ao examinar alguns livros no Museu Britânico. Essa análise revela que mulheres e ficção poderiam significar

alguns comentários sobre Fanny Burney [1752-1840]; alguns mais sobre Jane Austen [1775-1817]; um tributo às irmãs Brontë 4 e um esboço do Presbitério de Haworth sob a neve; alguns ditos espirituosos, se possível, sobre a srta. Mitford [Mary Russell Mitford (1787-1855)]; uma alusão respeitosa a George Eliot [Pseudônimo de Mary Ann Evans (1819-1880)], uma referência à sra. Gaskell ${ }^{5}$, e estaríamos conversados (WOOLF, 1985, p. 7).

Verificamos que, nesse comentário, Woolf (1985, p. 8) resume a um quadro ínfimo as mulheres significativas, encontradas no museu, relacionadas à ficção britânica. E acrescenta que "a mulher e a ficção [...] permanecem como problemas não solucionados", uma vez que se vale da opinião que "a mulher precisa ter dinheiro e um teto todo dela se pretende mesmo escrever ficção".

Com isso, veio-nos uma questão, após fazermos a leitura de todo o ensaio de Woolf: onde está a escritora inglesa Mary Shelley (1797-1851)? Não entrou no acervo do Museu Britânico? Uma vez que não encontramos referência alguma, nem como esposa do poeta inglês Percy Shelley (1792-1822), que é citado três vezes em todo o texto ${ }^{6}$ de Woolf. Será que há um

\footnotetext{
${ }^{4}$ Charlotte (1816-1855), que usou o pseudônimo de Currer Bell, Emily (1818-1848) e Anne (1820-1849) Brontë, escritoras inglesas (nota nossa).

${ }^{5}$ Elizabeth Gaskell (1810-1865), escritora inglesa. Para Fabio Cyrino (in GASKELL, 2011, p. 544), "ao longo do séc. XX, a produção literária de Elizabeth Gaskell foi considerada fora de moda e muito provincial, mas hoje é considerada pela grande maioria da crítica especializada como um dos grandes nomes da literatura vitoriana" (nota nossa).

${ }^{6}$ Woolf (1985) menciona, primeiro, ao encontrar, na estante, biografias de grandes homens, que, conforme ela, foram grandes por necessidade e dependência do sexo oposto: "E olhei novamente para a estante. Lá estavam as biografias: Johnson e Goethe e Carlyle e Sterne e Cowper e Shelley e Voltaire e Browning e muitos outros"
} 
silenciamento em relação a Mary Shelley nesse ensaio de Woolf? De acordo com Carlos Primati (SHELLEY, 2017, p. 238), o nome de Mary Shelley, até a metade da década de 1970, era "conhecido quase que exclusivamente pelo romance de horror e ficção científica Frankenstein, [...] e por seus esforços em publicar, postumamente, as obras do marido, [...] hoje é considerada uma das grandes figuras do romantismo inglês".

Com isso, este trabalho objetiva apresentar a autora inglesa Mary Shelley como iniciadora da ficção científica com Frankenstein ou o Prometeu moderno, e esta como uma obra matricial de autoria feminina, a fim de questionar a sua ausência no Museu Britânico e/ou os valores canônicos defendidos por Virginia Woolf, a partir de seus apontamentos sobre a mulher na ficção, no ensaio Um teto todo seu.

Em seu ensaio, Woolf (1985, p. 22) concorda com o que dizem da ficção, que ela "deve ater-se aos fatos, e, quanto mais verdadeiros os fatos, melhor a ficção". Será essa a questão? O tipo de narrativa escrita? Vimos, na primeira citação de Woolf, em nosso texto, a referência a Elizabeth Gaskell. Sabemos que "sua obra lança um olhar crítico e sorrateiro ao papel da mulher inglesa do século XIX, uma vez que realça o dinamismo das personagens femininas dessa época, rompendo algumas barreiras impostas pelos valores vitorianos ${ }^{7 \% "}$ (COSTA, 2017, p. 176). Gaskell foi contemporânea de Shelley, então, a não referência de Woolf, em seu ensaio, a Shelley poderá ter sido em decorrência da questão dos valores da época e o tipo de ficção que Shelley ousou criar? Quem foi realmente Mary Shelley? O que ela tanto escreveu? Que registros ficaram de sua escrita para a posterioridade? A época em que Woolf viveu terá tido oportunidade de conhecer o(s) texto(s) de Shelley? Qual a contribuição de Shelley para o mundo literário, e por consequência, artístico e cultural?

Notamos que Shelley teve aquilo que Woolf considera como a condição primeira para a mulher escrever ficção, "ter dinheiro e um teto todo seu". Para Alexander Silva (2006, p. 205), "nenhum outro romancista da literatura inglesa teve pais mais ilustres que Mary Wollstonecraft

(WOOLF, 1985, p. 107, grifo nosso). Segundo, quando revela que é fatal para um escritor não ser andrógino, como Shakespeare foi, "e também o eram Keats e Sterne e Cowper e Lamb e Coleridge. Shelley talvez fosse assexuado" (WOOLF, 1985, p. 126, grifo nosso). E, por último, ao citar as palavras do livro The art of writing [sic], de Sir Arthur Quiller-Couch, fazendo referência ao que contribui para a formação de um poeta: "Quais são os grandes nomes da poesia dos últimos cem anos, aproximadamente? Coleridge, Wordsworth, Byron, Shelley, Landor, Keats, Tennyson, Browning, Arnold, Morris, Rossetti, Swinburne - podemos parar por aqui" (WOOLF, 1985, p. 130, grifo nosso). Aqui, nenhuma mulher na lista de um século da poesia britânica. Um dos pontos levantados por Woolf para procurar entender e justificar o fato.

${ }^{7}$ Para Lúcia Zolin (2009, p. 220), "na Inglaterra, a condição social da mulher na Era Vitoriana (1832-1901) foi tenazmente marcada por diversos tipos de discriminações, justificadas com o argumento da suposta inferioridade intelectual das mulheres, cujo cérebro pesaria 2 libras e 11 onças, contra as 3 libras e meia do cérebro masculino. Resulta disso que a mulher que tentasse usar seu intelecto, ao invés de explorar sua delicadeza, compreensão, submissão, afeição ao lar, inocência e ausência de ambição, estaria violando a ordem natural das coisas, bem como a tradição religiosa". 
Shelley. Filha do filósofo [...] e líder reformista William Godwin [1756-1836] e da precursora do feminismo, autora de $A$ vindication of the rights of woman (1792), Mary Wollstonecraft ${ }^{8}$ ", nascendo "Mary Wollstonecraft Godwin, filha única de dois famosos defensores de ideias progressistas do século XVIII” (BRITO, 2017, p. 16); casou-se em 1816 com Percy Shelley, tornando-se Mary Wollstonecraft Shelley. Sobre a sua biografia, Silva acrescenta:

viúva aos vinte e quatro anos, ela teve de se sustentar através de sua escrita. Ainda que jamais tenha conseguido repetir o sucesso de seu primeiro romance, ela conquistou um relativo reconhecimento com seus outros cinco romances. Desses, os dois primeiros são os melhores: The Last Man (1826), 'o primeiro romance a mostrar o fim da humanidade devido a uma epidemia mundial', e Valperga (1823). Ela também realizou alguns estudos literários, divulgou a obra de seu marido e escreveu vinte e cinco $\operatorname{contos}^{10}$, dentre os quais se destacam The Mortal Immortal (1833) e Transformation (1831). (SILVA, 2006, p. 206).

$\mathrm{Na}$ busca por seus escritos, descobrimos que Mary Shelley escreveu History of a six week's tour through a part of France, Switzerland, Germany, and Holland: with letters descriptive of a sail round the Lake of Geneva, and of the Glaciers of Chamouni (1817), em parceria com Percy Shelley; Frankenstein: or, the modern Prometheus $(1818 ; 1823 ; 1831)^{11}$; Mathilda (1820); Valperga, or, The life and adventures of Castruccio, Prince of Lucca (1823); Posthumous poems of Percy Bysshe Shelley (1824), The last man (1826); The fortunes of Perkin Warbeck (1830); Lodore (1835); Falkner (1837); Notes to the complete poetical works of Percy Bysshe Shelley (1839); Rambles in Germany and Italy (1844) (BRITO, 2017).

Mary Shelley também escreveu as peças Proserpine e Midas, não publicadas ${ }^{12}$. Contribuiu para a escrita de biografias de portugueses, espanhóis, italianos (de 1835 a 1837) e franceses (de 1838 a 1839) ilustres em Lives of the most eminent literary and scientific men (1835-1839), fazendo parte do Lardner's cabinet cyclopaedia (1829-1846) (BRITO, 2017). Foi a única mulher a escrever para essa enciclopedia, dentre os demais escritores. Ademais, escreveu contos como Transformação (1831); O imortal mortal (1833); Roger Dodsworth: $O$ inglês reanimado; Valério: o romano reanimado etc. (PRIMATI, in SHELLEY, 2017),

\footnotetext{
${ }^{8}$ Mary Wollstonecraft (1759-1797), escritora inglesa e defensora dos direitos das mulheres, em sua obra $A$ Vindication of the Rights of Woman aponta a falta de educação e escolaridade como a causa da suposta inferioridade da mulher.

${ }^{9}$ Narrativa histórica, apresentando as mulheres na história, que não fazem parte do registro histórico (nota nossa).

${ }^{10}$ Encontramos trinta e um contos sob autoria de Mary Shelley (nota nossa).

11 Obra escrita em 1816, tendo sua primeira publicação em 1818, em Londres, em três tomos; com dedicação a William Godwin, prefácio de Percy Shelley, em 500 cópias e anônima. Uma segunda, em 1823, em dois tomos com algumas modificações; uma tiragem entre 250 a 500 cópias, já com o crédito de autora a Mary Shelley. E uma terceira, em 1831, revisada, corrigida, com as alterações de 1823, um capítulo adicional, uma introdução da autora, em um único volume (BRITO, 2017). É esta última que usamos sua tradução para a escrita de nosso trabalho.

${ }^{12}$ Atualmente estão disponíveis para leitura no site: http://www.gutenberg.org/files/42324/42324-h/42324-h.htm
} 
publicou contos como "The sisters of Albano" (1829) e "Ferdinando Eboli" (1829) na coletânea The Keepsake ${ }^{13}$, de 1829 a 1839 (FELDMAN, 2006), assim como escreveu ensaios para revistas especializadas da época.

Tudo isso nos surpreendeu, então continuamos à procura de mais informações e críticas acerca das suas obras. Uma delas foi a do escritor estadunidense Howard P. Lovecraft (18901937), em seu livro $O$ horror sobrenatural em literatura - quando aborda "os desdobramentos da ficção gótica”. Ele considera William Godwin como pertencente à tradição gótica europeia, destacando-se com a escrita de Caleb Williams (1794) e, em grau menor, St Leon (1799), porém,

sua filha, Mary, esposa de Shelley, se saiu bem melhor, e seu inimitável Frankenstein;
or, the Modern Prometheus (Frankenstein; ou, o moderno Prometeu), 1817 [sic], é
um dos clássicos de horror de todos os tempos. Composto numa competição com seu
marido, Lorde Byron e o Dr. John William Polidori ${ }^{14}$ na tentativa de provar
supremacia na criação de horror, Frankenstein da Sra Shelley foi a única narrativa
concorrente que recebeu um acabamento elaborado; e a crítica não conseguiu provar
que as melhores partes se devem ao poeta Shelley e não a ela. (LOVECRAFT, 2012,
p. 44 , grifos nossos).

Referindo-se a Frankenstein, o escritor brasileiro José Paulo Paes, em seu livro Gregos e baianos (1985), afirma: "trata-se do grande, senão único mito original produzido pela idade da ciência e da técnica, a cujos primórdios sua autora assistiu na Inglaterra e cuja culminação estamos hoje vivendo pelo mundo todo com o advento da cibernética e da engenharia genética" (PAES, 1985, p. 232). Então, Frankenstein pode ser considerado o iniciador da ficção científica, uma vez que esse gênero ainda não estava formado em 1818, data de sua primeira publicação em Londres?

Conforme Silva (2006, p. 210), “devido à importância do elemento científico na trama, Frankenstein é considerado a primeira obra da ficção científica da história”. No entanto, ele acrescenta que, "apesar de Frankenstein, as irregularidades das outras obras não permitiram que Mary Shelley fosse considerada a principal voz da prosa romântica” inglesa (SILVA, 2006, p. 211). Essa posição foi assumida por Walter Scott (1771-1832) e, em seguida, por Jane Austen (SILVA, 2006). Então, com isso, Mary Shelley seria a terceira ficcionista da Era Romântica britânica?

\footnotetext{
${ }^{13}$ Anuário literário inglês, publicado a cada Natal, de 1828 a 1857, com textos de autores diversos. Pelo ponto de vista histórico, o Anuário de 1829 foi o mais importante deles, com textos de Felicia Hemans, Letitia Landon, Mary Shelley, Percy Shelley, S. T. Coleridge, Thomas Moore, Walter Scott, William Wordsworth etc. (FELDMAN, 2006).

${ }^{14}$ John William Polidori (1795-1821), médico e escritor inglês, escreveu The Vampyre (1819). De acordo com Silva (2006, p. 206), "essa é a primeira história em prosa sobre vampiros da literatura inglesa, e serviu de inspiração para Bram Stoker [1847-1912] escrever Drácula (1987)”.
} 
O escritor estadunidense Stephen King (1947-), no prefácio da antologia Frankenstein, Drácula e O médico e o monstro (2001), considera Frankenstein como o iniciador da ficção científica tal qual a conhecemos hoje, e um dos três grandes clássicos da literatura de terror. À vista disso, por que Mary Shelley está fora do Museu Britânico, ou dos olhos de Woolf? Por que Woolf não menciona Shelley em seu ensaio, quando faz referência às escritoras do século XIX? Frankenstein, de Shelley, "falhou em algum ponto" (WOOLF, 1985, p. 90)? Qual?

Conforme Carlos Primati, Mary Shelley é tida como um caso exemplar, uma vez que a obra supera seu autor, imortalizando-se com Frankenstein, um sucesso imediato que causou grande impacto na literatura e, mais ainda, em sua autora. "O conceito da criação de vida artificial e reanimação de tecidos mortos (ou adormecidos) - tão inovador e ousado quanto grotesco e repugnante; por isso mesmo, transitando entre a ficção especulativa e o horror gótico" (, 2017, p. 238). Seria isso? Transitar entre a literatura dita popular? Marginal? Questões canônicas ${ }^{15}$ ? Pelo horror gótico? Para Lovecraft (2012, p. 44-45, grifo do autor), a novela de Mary Shelley,

um pouco marcada, mas pouco prejudicada pelo didatismo moral, conta a história do ser humano artificial criado a partir de pedaços de cadáveres por Victor Frankenstein, um jovem pesquisador médico suíço. Criado por seu idealizador 'no orgulho insano de intelectualidade', o monstro ${ }^{16}$ tem plena inteligência, mas sua forma é repulsiva. Ele é rejeitado pela humanidade, fica amargurado e, por fim, trata de assassinar sucessivamente todos aqueles de que Frankenstein mais gosta, amigos e familiares. Ele exige que Frankenstein crie uma esposa para ele, e quando o cientista, por fim, se recusa horrorizado temendo que o mundo seja povoado por monstros assim, ele parte com a ameaça terrível 'de estar com ele na sua noite de núpcias'. Nessa noite, a noiva é estrangulada e, desse momento em diante, Frankenstein sai a caça do monstro que ele persegue até a vastidão do Ártico. No fim, procurando abrigo no navio do narrador da história, o próprio Frankenstein é morto pelo objeto estarrecedor de sua busca e criação de seu orgulho presunçoso. [...] A Sra. Shelley escreveu outros romances, inclusive o notável Last Man (O último homem), mas nunca repetiu o sucesso do seu primeiro esforço. Ele tem o verdadeiro toque de medo cósmico, por mais que a ação possa se arrastar em certos pontos. (LOVECRAFT, 2012, p. 44-45, grifo do autor).

Pelas palavras de Lovecraft, percebemos um pouco da filosofia usada por Mary Shelley na obra Frankenstein. Esse tipo de postura é aprovado por Woolf, em seu ensaio, ao expor que “a ficção estará muito melhor em grande intimidade com a poesia e a filosofia” (WOOLF, 1985,

\footnotetext{
15 “A gente só entra no cânone pela força poética, que se constitui basicamente de uma amálgama: domínio da linguagem figurativa, originalidade, poder cognitivo, conhecimento, dicção exuberante" (BLOOM, 1994, p. 36). "Para o cânone as relações de influência entre escritores atuais e antigos é essencial" (DIOGO, 1999, p. 323-324). Para Reis (1992, p. 77), a existência de um cânon é problemática devido reduplicar as relações injustas que compartimentam a sociedade.

${ }^{16} \mathrm{Na}$ obra de Shelley, o Dr. Victor Frankenstein não nomeia o ser que criou, reportando-se sempre a ele com os termos: criatura, monstro, demônio. Passando a vagar durante toda a narrativa sem designação, excluída da sociedade, como "uma nódoa sobre a face da Terra, da qual todos os homens fugiam e que todos os homens repudiavam” (SHELLEY, 2011, p. 134).
} 
p. 133). Também observamos, pela leitura de Shelley, no fragmento a seguir, a busca da filosofia para a tessitura de Frankenstein:

\begin{abstract}
Muitas e longas eram as conversas entre Lorde Byron e Shelley, as quais eu ouvia devotada, mas praticamente silenciosa. Durante uma delas, debateram várias doutrinas filosóficas e, entre elas, a natureza do princípio da vida e se acaso existia alguma possibilidade de este ser descoberto e comunicado. Falaram das experiências do dr. Darwin ${ }^{17}$. [...] talvez um cadáver pudesse ser reanimado. O galvanismo ${ }^{18}$ já dera uma amostra de tais coisas. (SHELLEY, 2017, p. 28).
\end{abstract}

Apesar da modéstia de Mary Shelley, sabemos por Brito (2017, p. 17) que Shelley "tinha certa iniciação científica e treino filosófico pelo ambiente cultural do lar paterno”. Ademais, acrescentamos que ela respirava poesia pelo entorno familiar e de amigos, e ainda pela própria efervescência do romantismo inglês ${ }^{19}$. Fato que poderá ter contribuído no artifício que usa ao intercalar, vez por outra, a narrativa de Frankenstein com versos de inúmeros poemas de autores renomados, tais como, na própria epigrafe da obra, que traz quatro versos de Paradise lost (1667), de John Milton (1608-1674); ao longo do texto, constatamos versos de Mutability (1816), de Percy Shelley, Tintern Abbey (1798), de William Wordsworth (1770-1850) e outros. Transcrevemos um trecho, para exemplificação, após o momento em que Frankenstein dá vida a sua criatura e foge de temor por seu ato, no capítulo cinco, onde um excerto da poesia de Samuel Coleridge (1772-1834), "The rime of the ancient mariner" (1798), interpõe-se a narrativa de Shelley, dando continuidade aos eventos ocorridos:

\begin{abstract}
Atravessava as ruas sem qualquer ideia nítida sobre onde estava ou o que fazia. $\mathrm{O}$ medo me dava náuseas e acelerava-me o coração; eu seguia apressado, com passos irregulares, sem ousar olhar ao meu redor:

Como alguém que, numa estrada solitária, / Anda com medo e apreensão / E tendo uma vez se voltado, segue em frente / E não olha mais para trás; / Porque sabe que um demônio terrível / Segue-o bem de perto.

Prosseguindo, cheguei, enfim, [...] (SHELLEY, 2011, p. 68-69, grifo da autora).
\end{abstract}

Será que, com esse recurso, Mary Shelley busca reverenciar outros autores consagrados? Os "grandes poetas"? Uma tentativa de ser aceita por eles ou por seus leitores? Ou uma questão de estilo? De conhecimento literário? De acordo com T. S. Elliot (1989, p. 39), "nenhum poeta, nenhum artista, tem sua significação completa sozinho. Seu significado e a apreciação que dele

\footnotetext{
${ }^{17}$ Dr. Erasmus Darwin (1731-1802) médico e naturalista inglês, inventou alguns objetos. Avô de Charles Darwin (BRITO in SHELLEY, 2017, p. 22, em nota).

${ }^{18}$ O galvanismo foi uma teoria de Luigi Galvani (1737-1798) (BRITO in SHELLEY, 2017, p. 28, em nota).

${ }^{19} \mathrm{O}$ romantismo inglês inicia em 1798 com a publicação de Lyrical Ballads, de Wordsworth e Coleridge. Um misto de lendário, de retorno à natureza, e, de mágico e misterioso (BURGESS, 2002).
} 
fazemos constituem a apreciação de sua relação com os poetas e os artistas mortos”. Com isso, seria uma questão de seguir a tradição?

Ao retornar a Um teto todo seu, percebemos os questionamentos que Woolf (1985) faz acerca da desigualdade de direitos entre homens e mulheres na sociedade e as consequências disso para as mulheres e a ficção, uma vez que a pobreza é o que resta para essas mulheres. Observamos que Woolf confessa sentir raiva e outros sentimentos negativos ao mencionar o professor Von X, que escreveu sobre A inferioridade mental, moral e física do sexo feminino. Ela admite que "a raiva se apossara de meu lápis" (WOOLF, 1985, p. 40) e mais adiante, "eu enrubescera de raiva. Por tolo que fosse, não havia nisso nada de especialmente notável. Não gostamos que nos digam que somos por natureza inferiores a um homenzinho" (Ibid., p. 41).

Entretanto, no capítulo IV, Woolf critica Charlotte Brontë (1816-1855) pela escrita de Jane Eyre (1847), que Brontë o fez deixando transbordar as mágoas e raivas guardadas em suas entranhas, vivenciadas sob uma sociedade inglesa conservadora, revelando ódio, quando deveria mostrar tranquilidade, escrevendo de "maneira tola, quando deveria escrever com sabedoria" (Ibid., p. 87), escrevendo sobre "si mesma, quando deveria escrever sobre suas personagens" (Ibid., p. 87). Dessa forma, para Woolf, ela jamais conseguiria "expressar seu talento integral e completamente" (Ibid., p. 87). Mesmo assim, com farpas, Woolf a considera, em seu ensaio, como um dos quatro nomes de escritoras inglesas famosas do século XIX.

De acordo com Woolf (1985), a mulher elisabetana - observando um livro de história do professor Trevelyan - não deixou registros, salvo "uma Elizabeth ${ }^{20}$ ou Mary ${ }^{21}$, uma rainha ou grande dama" (Ibid., p. 57) mereceu a atenção na "visão de passado do historiador" (WOOLF, Ibid., 57). Ela acrescenta que "a mulher jamais escreve sobre a própria vida e raramente mantém um diário - existe apenas um punhado de suas cartas. Não deixou peças ou poemas pelos quais possamos julgá-la" (Ibid., p. 57). Assim, Woolf sugere que alunas de universidades britânicas famosas reescrevam a história, uma vez que ela parece "irreal e tendenciosa" (Ibid., p. 58), principalmente, por não encontrar informações sobre as mulheres antes do século XVIII. Em suma, ela admite que a mulher, na imaginação,

\footnotetext{
${ }^{20}$ Elizabeth Tudor (1533-1603), Rainha Elizabeth I, conhecida como a "Rainha Virgem", "Gloriana”, a última da linhagem dos Tudor, sucedeu a Mary I de 1558 até sua morte como rainha da Inglaterra, Irlanda e França. Em seu governo, a Inglaterra chegou ao apogeu, vivendo sua Era de Ouro nos campos econômico, político e cultural. Este floresceu com as artes, principalmente, com o teatro, a poesia e o ensaio. A Era Elisabetana foi o nome atribuído a esse período da história renascentista inglesa, reinado e governado por essa mulher.

${ }^{21}$ Mary Tudor (1516-1558), conhecida como Mary I, foi a primeira mulher a ser coroada por seu direito como rainha da Inglaterra, Irlanda e França de 1553 até sua morte, e da Espanha por matrimônio com o Rei Felipe II desde 1556, quando este ascendeu ao trono espanhol.
} 
é da mais alta importância, em termos práticos, é completamente insignificante. Atravessa a poesia de uma ponta à outra; por pouco está ausente da história. Domina a vida de reis e conquistadores na ficção, na vida real é escrava de qualquer rapazola cujos pais lhe enfiassem uma aliança no dedo. Algumas das mais inspiradas palavras, alguns dos mais profundos pensamentos saem-lhe dos lábios na literatura; na vida real, mal sabia ler e escrever e era propriedade do marido. (WOOLF, 1985, p. 56).

Esta realidade da mulher elisabetana implicava, de acordo com Woolf (1985), como os trabalhadores das classes operárias, na escassez da genialidade de William Shakespeare, contudo, "alguma espécie de talento deve ter existido entre as mulheres, como deve ter existido entre as classes operárias. Vez por outra, uma Emily Brontë, ou um Robert Burns ${ }^{22}$, explode numa chama e prova sua presença. Mas certamente esse talento nunca chegou ao papel” (WOOLF, 1985, p. 61-62).

Woolf (1985, p. 62) supõe que "Anônimo, que escreveu tantos poemas sem assiná-los, foi muitas vezes uma mulher", no intuito de fugir das violências da sociedade da época. Ademais, "o que quer que houvesse escrito teria sido distorcido e deformado" (Ibid., p. 63), se viesse da mão de uma mulher. Ela acrescenta que essas privações, para o anonimato das mulheres, chegaram até mesmo ao século XIX. Como vimos na primeira edição de Frankenstein, de Shelley (conforme nota 8). "Currer Bell, George Eliot, George Sand ${ }^{23}$, todas vítimas do conflito interno, como provam seus escritos, buscaram inutilmente esconder-se atrás de nomes masculinos. Assim, renderam homenagem à convenção" (Ibid., p. 64). Apesar disso, aqui, encontramos dois dos quatro nomes de escritoras inglesas famosas do século XIX considerados por Woolf - George Eliot e Charlotte Brontë.

Para Woolf (1985, p. 68), é "bastante evidente que, mesmo no século XIX, a mulher não era incentivada a ser artista. Pelo contrário, era tratada com arrogância, esbofeteada, submetida a sermões e admoestada". Todavia, na introdução da terceira edição de Frankenstein, encontramos a seguinte revelação:

meu marido, contudo, mostrou-se desde o início muito desejoso de que eu provasse estar à altura de meus pais e que ingressasse no rol das celebridades. Sempre me incitou a adquirir uma reputação literária, o que importava-me na época, embora, desde então, tenha me tornado imensamente alheia a isso. Nessa ocasião, ele desejava que escrevesse, não com a ideia de que fosse produzir algo digno de atenção, mas para que pudesse julgar se guardava a promessa de coisas melhores na vida futura. (SHELLEY, 2017, p. 25).

\footnotetext{
${ }^{22}$ Robert Burns (1759-1796), poeta escocês.

${ }^{23}$ Pseudônimo de Amandine Aurore Lucile Dupin (1804-1876), baronesa de Dudevant, escritora francesa.
} 
Constatamos com essa confissão de Mary Shelley, que ela foi uma possível exceção às evidências de Woolf. Mas, pelo visto, não foi digno de nota para mencioná-la em seu ensaio, ou tão pouco ser vista, se realmente estava, em alguma prateleira do museu.

Woolf (1985, p. 70-71) considera Shakespeare como uma mente que escreveu em um estilo incandescente, sem interferências externas em sua escrita, na qual "seus ressentimentos e rancores e antipatias nos são ocultados". Seus textos fluem livres e desimpedidos, frutos de um estado de espírito que ela acredita ser mais propício ao ato criativo. Próprio de uma mente brilhante que ela não percebe comparação na estante que observa do museu.

Também, Woolf (1985, p. 73) afirma que é impossível encontrar mulheres no século XVI com "essa disposição de ânimo". Contudo, o que se pode encontrar são mentes perturbadas por "medo e ódio", interferindo em seus escritos como, um pouco adiante no tempo, a de Lady Winchilsea, nascida em 1661, nobre por nascimento e casamento, e sem filhos, que escreveu poesia de forma "atormentada e desvirtuada por ódios e ressentimentos" (WOOLF, 1985, p. 74), não eliminando todos os empecilhos que pudesse torná-la brilhante. Ao invés, explode de “indignação contra a posição da mulher" (Ibid., p. 74).

Assim, Woolf dirige-se a estante do século XVIII, afirmando que centenas de mulheres passam a contribuir com suas despesas pessoais ou com o provimento de suas famílias, “fazendo traduções ou escrevendo os inúmeros romances de má qualidade" (Ibid., p. 81). O que, para ela, foi de extrema importância para a história, essa mudança de comportamento, principalmente, quando “a mulher da classe média começou a escrever" (Ibid., p. 82). Ela justifica que sem os precursores um poeta não teria tido a possibilidade de escrever:

sem aquelas precursoras [Kathleen Philips (1631-1664) - poeta; Eliza Haywood (1693-1756) - dramaturga e romancista; Aphra Behn (1640-1689) - dramaturga, poeta e romancista, e uma das primeiras mulheres a viver do que escrevia etc.], Jane Austen e as irmãs Brontë e George Eliot não teriam tido maior possibilidade de escrever do que teria Shakespeare sem Marlowe ${ }^{24}$, ou Marlowe sem Chaucer ${ }^{25}$, ou Chaucer sem aqueles poetas esquecidos que prepararam o terreno e domaram a selvageria natural da língua. As obras primas não são frutos isolados e solitários; são o resultado de muitos anos de pensar em conjunto, de um pensar através do corpo das pessoas, de modo que a experiência da massa está por trás da voz isolada. (Ibid., 82).

Então, como Elliot (1989), uma questão de seguir a tradição? Notamos que Shelley tem uma estrada aberta, precursores como os pais, esposo e amigos literatos, muitas experiências de viagens pela Europa, “no verão de 1816, visitamos a Suíça e tornamo-nos vizinhos de Lorde

\footnotetext{
${ }^{24}$ Christopher Marlowe (1564-1593), escritor inglês da Era Elisabetana.

${ }^{25}$ Geoffrey Chaucer (1343-1400), diplomata, escritor e filósofo inglês.
} 
Byron" (SHELLEY, 2017, p. 25), a educação, a época eletrocientífica, gótica ${ }^{26}$ e romântica etc. "Não é de estranhar que, como filha de duas pessoas de distinta notoriedade literária, eu devesse muito cedo na vida ter pensado em escrever" (Ibid., p. 24).

Em suas observações sobre as escritoras do século XIX, Woolf (1985, p. 83) afirma que encontrou, desta vez, diversas prateleiras, na biblioteca, "dedicadas às obras de mulheres", contudo, considera quatro nomes famosos: Jane Austen, Emily Brontë, George Eliot e Charlotte Brontë. Mais uma vez, nada sobre Mary Shelley. E, a pergunta lancinante, por que Shelley não estaria visível na estante do Museu Britânico? Por que Woolf não a encontra para suas referências?

Woolf (1985, p. 85) realça que como Shakespeare, a mente de Jane Austen destruiu todos os obstáculos, “escrevendo sem ódio, sem amargura, sem medo, sem protestos, sem pregações”. Ela afirma que as mulhes escritoras no século XIX alteram seus próprios valores em respeito a opinião alheia, pois na opinião dos críticos da época, eram os valores masculinos que prevaleciam. Com relação a alteração de seus valores, devido à opinião patriarcal da época, para Woolf (1985, p. 92-93), “apenas Jane Austen conseguiu, e Emily Brontë. [...] Elas escreveram como as mulheres escrevem, e não como os homens. [...], somente elas ignoraram por completo as admoestações perpétuas do eterno pedagogo - escreva isto, pense aquilo". Porém,

\begin{abstract}
em meados daquele mês de agosto [1816], a autora [Mary Shelley] escreveu uma história que se tornou a base para o primeiro rascunho completo do romance [Frankenstein]. A maior parte deste rascunho completo está preservado até hoje, juntamente com uma parte da versão final manuscrita pela própria autora, na Bodleian Library, da Universidade de Oxford. Na versão revisada, é possível notar a ajuda editorial de Percy Shelley através de algumas anotações nas margens (BRITO in SHELLEY, 2017, p. 18).
\end{abstract}

Mas, Mary Shelley confessa como sucedeu a ideia que tomou forma e chegou ao mundo depois de uma simples aposta entre amigos em encontros decorrentes de um verão sombrio ${ }^{27}$ :

\footnotetext{
${ }^{26}$ Segundo Silva (2006, p. 183), o romance gótico foi um "tipo de literatura muito popular no período de 1760 até 1820 que exerceu profunda influência nas histórias de terror [...] assim como também no nascimento da literatura de massa. Ela apareceu como uma reação da imaginação ao racionalismo e ao moralismo que marcaram o Iluminismo e a literatura neoclassicista do século XVIII". Para Lovecraft (2012, p. 26), coube ao inglês Horace Walpole (1717-1797) ser o "fundador da história de horror literária como forma permanente", publicando em 1764, The Castle of Otranto ( $O$ Castelo de Otranto), inaugurando os primórdios da novela gótica. Conforme Silva (2006, p. 185), a evolução do romance gótico ocorre "com a publicação em 1818 de Frankenstein, de Mary Shelley, é a ciência que passa a fascinar e ao mesmo tempo a aterrorizar as pessoas".

27 "O verão [de 1816] revelou-se, porém, bem pouco propício, úmido, e uma chuva incessante várias vezes nos deixava confinados à casa durante dias" (SHELLEY, 2011, p. 13).
} 
Foi então que irrompeu a ideia, rápida como um raio e bastante animadora. 'Achei! O que me havia aterrorizado certamente encheria os outros de pavor; apenas preciso descrever o espectro que me assombrou à meia-noite!' Pela manhã, anunciei que pensara em uma história. Comecei naquele dia com as palavras: Foi em uma noite sombria de novembro, fazendo meramente a transcrição dos terrores cruéis de meu sonhar acordada. [...] Primeiramente, pensei apenas em algumas páginas, um conto curto, mas Shelley incitou-me a desenvolver a ideia com mais fôlego. Por certo não devo a sugestão de um só incidente nem dificilmente de uma linha sequer de pensamento ao meu marido, e ainda assim, não fosse por seu estímulo, a história nunca teria tomado a forma que apresentei ao mundo. Dessa declaração, devo excetuar o prefácio. Tanto quanto me recordo, foi escrito por ele (SHELLEY, 2017, p. 29, grifos da autora).

Uma parte das críticas às obras de Mary Shelley não é boa, é áspera, rancorosa, como podemos observar na citação seguinte, onde o autor faz uma crítica vazia, já que não aponta exemplos do texto de Mary Shelley:

Frankenstein é um dos romances mais analisados da literatura inglesa. Ele já foi objeto de análises psicológicas, científicas, marxistas, feministas, homossexuais e póscolonialistas. $\mathrm{O}$ interessante é que há uma concordância geral entre os críticos de que o romance tem vários defeitos que variam da falta de estilo narrativo de Shelley á [sic] problemas na trama. Então por que ele resiste a tanto tempo como um dos romances mais populares da literatura universal? De fato, no início de seus estudos em literatura inglesa é mais fácil um aluno conhecer Mary Shelley, devido ao romance, do que seu marido Percy Shelley, que foi um dos maiores poetas da Inglaterra (SILVA, 2006, p. 207, grifos nossos).

Todavia, as estruturas profundas de Frankenstein ou o Prometeu moderno são seguidas e/ou copiadas tanto na literatura quanto no cinema (nesta modalidade encontramos 26 filmes de 1910 a 2015 adaptados de Frankenstein ${ }^{28}$ ). A sua primeira publicação foi traduzida para o francês e adaptada ao teatro. A obra já foi, também, adaptada para o rádio, TV, cinema e quadrinhos.

\footnotetext{
${ }^{28}$ Em 1910, Frankenstein ou o Prometeu moderno (mudo), produção de Thomas Edison; Frankenstein (1931), de James Whale; A noiva de Frankenstein (1935), de James Whale; O filho de Frankenstein (1939), de Rowland V. Lee (com o húngaro Béla Lugosi como ator); O fantasma de Frankenstein (1942), de Erle C. Kenton (com o húngaro Béla Lugosi como ator); Frankenstein encontra o Lobisomem (1943), de Roy William Neill (com o húngaro Béla Lugosi como ator); A casa de Frankenstein (1944), de Erle C. Kenton; Às voltas com fantasmas (Abbott and Costello Meet Frankenstein) (1948), de Charles Barton (com o húngaro Béla Lugosi como ator); A maldição de Frankenstein (1957), de Terence Fisher; A vingança de Frankenstein (1958), de Terence Fisher; $O$ monstro de Frankenstein (1964), de Freddie Francis; Frankenstein criou a mulher (1967), de Terence Fisher; Frankenstein tem que ser destruído (1969), de Terence Fisher; Horror de Frankenstein (1970), de Jimmy Sangster; A verdadeira história de Frankenstein (1973), de Jack Smight; Frankenstein e o monstro do inferno (1974), de Terence Fisher; O jovem Frankenstein (1974), de Mel Brooks; Frankenstein (1984), de James Ormerod; Frankenweenie (1984), de Tim Burton (curta-metragem); A prometida (1985), de Frank Roddam; Gótico (1986), de Ken Russell; Frankenstein de Mary Shelley (1994), de Kenneth Branagh; Van Helsing (2004), de Stephen Sommens - a criatura de Frankenstein faz uma aparição no roteiro; Frankenweenie (2012), de Tim Burton (animação em 3D); Frankenstein: Entre anjos e demônios (2014), de Stuart Beattie; Victor Frankenstein (2015), de Paul McGuigan; Frankenstein (FRANK3N5T31N) (2015), de Bernard Rose etc. (SANTOS, 2015).
} 
"Os textos das três edições diferem entre si, bem como distam substancialmente dos textos do primeiro rascunho de 1816 e da primeira cópia manuscrita feita pela própria autora, em especial na numeração e estrutura de divisão dos capítulos” (BRITO, 2017, p. 19). No entanto, Mary Shelley diz que

acrescentaria apenas uma palavra quanto às alterações que fiz. São, principalmente, no estilo. Não mudei parte alguma da história nem introduzi novas ideias ou circunstâncias. Corrigi a linguagem onde estava tão pobre que pudesse interferir no interesse da narrativa. Essas mudanças aconteceram quase exclusivamente no início do primeiro volume. Estão confinadas, todas, a tais partes como meros acessórios à história, deixando intocados o âmago e a substância (SHELLEY, 2017, p. 29).

Com relação à escrita autobiográfica, Woolf (1985), em seu ensaio, questiona se as escritoras do século XX esgotaram o impulso de escrever autobiografias, como as do passado, ironizando que "talvez a mulher esteja começando a usar a literatura como arte, não como um método de expressão pessoal" (WOOLF, 1985, p. 99). E, pelas palavras de Mary Shelley (2017, p. 25), na introdução da terceira edição de Frankenstein, percebemos que ela contradiz o pensamento de Woolf, ainda no início do século XIX: "Escrevi então, ainda que em um estilo mais trivial. [...] Não me fiz heroína de minhas histórias. Quanto a mim mesma, a vida parecia um assunto bastante banal". Mais uma vez, outro ponto referido por Woolf passa despercebido pelos seus olhos observadores.

Mary Shelley (2011, p. 17) salienta, ainda no final de sua introdução, convidando sua "medonha criação a seguir adiante e prosperar. Tenho certa afeição por esta obra, pois é fruto de dias felizes, quando a morte e o sofrimento não passavam de palavras que não encontravam qualquer ressonância verdadeira em meu coração". Com essa leitura, podemos inferir que Shelley escapa do autobiografismo citado por Woolf? Então, será que Mary Shelley já estava usando a literatura como arte, nos dizeres de Woolf (1985)? Ou melhor, estava inventando arte? Seguindo a tradição? (Re)Criando a partir do antigo? Vejamos Shelley (2017, p. 27) contar as suas ideias sobre a invenção:

Tudo deve ter um começo, para usar um dito de Sancho Pança ${ }^{29}$, e esse começo deve estar relacionado a alguma coisa que já existiu antes. Os hindus deram ao mundo um elefante para que o carregasse, mas fizeram o elefante postar-se em cima de uma tartaruga. A invenção, devemos admitir humildemente, não consiste em criar do nada, mas do caos; os materiais devem, em primeiro lugar, ser concedidos; ela pode dar forma a substâncias disformes, obscuras, mas não pode trazer à existência a própria substância. Em todas as questões de descoberta e invenção, mesmo as que pertençam à imaginação, somos continuamente lembrados da história do ovo de Colombo [“Tudo

\footnotetext{
${ }^{29}$ Personagem contraponto de Dom Quixote, da obra Don Quixote de la Mancha (1605 - parte I; 1615 - parte II), do espanhol Miguel de Cervantes (1547-1616).
} 
que é natural parece fácil após conhecido ou encontrado. A dificuldade está em ser o inventor, o primeiro a conhecer ou a demonstrar" (COLOMBO apud BRITO, 2017, p. 27, em nota)]. A invenção consiste na capacidade de apreender as possibilidades de um objeto e no poder de moldar e adaptar as ideias que lhe são sugeridas.

Segundo Woolf (1985, p. 127), é fatal escrever pensando em seu sexo, “é fatal ser um homem ou uma mulher, pura e simplesmente; é preciso ser masculinamente feminina, ou femininamente masculino". Para Woolf, é preciso ter um equilíbrio na mente, entre os dois lados, "antes que a arte da criação possa realizar-se" (WOOLF, 1985, p. 127), e, assim, o escritor consiga comunicar-se com integridade, livre de ressentimentos, pois se "advogar mesmo com justiça, qualquer causa; de qualquer modo, falar conscientemente como mulher. [...] qualquer coisa escrita com essa tendência consciente está condenada a morte" (WOOLF, 1985, p. 127).

Vamos a Frankenstein. Ao mirarmos a obra de Shelley, podemos dizer que ela é estruturada em cinco cartas escritas pelo capitão Robert Walton, destinadas à irmã, na Inglaterra, a Sra. Margaret Saville, dando notícias de sua aventura marítima pelo "Pacífico Norte através dos mares que cercam o pólo" (SHELLEY, 2011, p. 22). Na quarta carta, ele relata o encontro com o Dr. Victor Frankenstein: "Ocorreu-nos um acidente tão estranho que não posso abster de registrá-lo [...]” (SHELLEY, 2011, p. 30).

\footnotetext{
Disse-me então que começaria sua narrativa no dia seguinte, quando eu estivesse de folga. [...] Decidi registrar, todas as noites em que meus afazeres não me ocuparem de forma imperativa, e tanto quanto possível em suas próprias palavras, o que ele me tiver relatado ao longo do dia. Se eu estiver ocupado, pelo menos farei anotações. Este manuscrito, sem dúvida, proporcionará a você um enorme prazer; [...] deve ser estranho e angustiante, e assustadora a tempestade que arrebatou o navio gigante em sua rota e destruiu-o - Assim!” (SHELLEY, 2011, p. 38.)
}

A partir daqui, Frankenstein narra sua história (do capítulo I ao XXIV) e o narratário imediato deixa de ser a destinatária da carta e passa a ser o capitão Walton. O narratário mediato (indireto) passa a ser a irmã de Walton e o leitor real fica em terceiro plano. Dentro da narrativa de Victor acontece ainda a narrativa da criatura (do capítulo XI até o XVI - aqui temos o ponto de vista do outro), e, também, outras cartas são trocadas, distanciando ainda mais os narratários. Com a morte de Frankenstein, Walton retoma o relato em cinco cartas registradas de 26 de agosto até 12 de setembro de 17 ... Indicando o século anterior a escrita dos eventos narrados na obra.

A narrativa segue em torno da figura masculina (personagens centrais). Nas cartas há a ênfase na coragem e determinação desbravadora dos homens, seria a estratégia que Shelley encontrou para ser aceita ou lida no século XIX? Ou ela estaria sendo andrógina? 
Femininamente masculino, buscando o equilíbrio da mente apontado por Woolf (1985)? Por outro lado, será que Shelley escreveu criticando os homens, focando o seu lado sombrio, mostrando as consequências de seus atos na sociedade? Será que Shelley não tinha uma “sensibilidade muita ampla, ávida e livre”, típica a que defende Woolf (1985, p. 114)? Ou será que se "iluminava diante de pequeninas coisas e mostrava que, afinal, talvez não fossem pequeninas" (WOOLF, 1985, p. 114)? Será que Shelley não "escreveu como mulher”, nas palavras de Woolf (1985, p. 115)? E o que podemos dizer do trecho seguinte, narrado por Victor Frankenstein?

Foi no final de setembro que mais uma vez deixei meu país natal. A viagem havia sido sugerida por mim, e, portanto, Elizabeth aquiescera, mas estava inquieta com a ideia de meu sofrimento, longe dela, e das incursões da tristeza e do pesar. Em seu zelo, cuidara para me proporcionar um companheiro, Clerval - e ainda assim um homem é sempre cego a centenas de pequenos fatos que revelam a atenção diligente de uma mulher (SHELLEY, 2011, p. 169-170).

Woolf (1985), ao fazer a leitura de Coleridge sobre a mente andrógina, explica que é possível que isso seja uma mente "que transmite emoções sem empecilhos; que é naturalmente criativa, incandescente e indivisa" (WOOLF, 1985, p. 121). Ela reafirma que Shakespeare escreve com prazer, não como protesto. Não "está protestando contra a igualdade do outro sexo através da afirmação da própria superioridade” (WOOLF, 1985, p. 123). Woolf (1985, p. 123124, grifo nosso) acrescenta que "a literatura elisabetana teria sido muito diferente do que é se o movimento feminista tivesse começado no século XVI e não no XIX’. Daqui, podemos inferir que a mãe de Mary Shelley, também, não estaria visível nas prateleiras do Museu Britânico?

Ao analisar a escrita masculina do museu, Woolf (1985) explica que não é apenas o fato que os homens "celebrem virtudes masculinas, imponham valores masculinos e descrevam o mundo dos homens; é que a emoção de que esses livros estão permeados é incompreensível para uma mulher" (WOOLF, 1985, p. 124), levando-lhe ao assombro, ao contrário, para o homem, é tão profunda, sútil e simbólica (WOOLF, 1985). Ela cita como exemplo Kipling ${ }^{30}$ que não tem "em si a centelha da mulher. [...] Falta-lhe o poder de sugestão" (WOOLF, 1985, p. 125). Voltando-nos para Shelley, será que ela não tem a centelha do homem? O poder de sugestão?

\footnotetext{
${ }^{30}$ Joseph Rudyard Kipling (1865-1936), escritor e poeta britânico, nascido na Índia britânica (SILVA, 2006). Foi o mais jovem e o primeiro autor de expressão inglesa a receber o Prêmio Nobel de Literatura em 1907. Disponível em: http://www.nobelprize.org/nobel_prizes/literature/laureates/index.html Acesso em: 4 ago. 2017.
} 
Percebemos que Frankenstein, de Shelley, reproduz os valores do século XVIII europeu, o tempo da narrativa, como por exemplo, o ideal do casamento como opção de realização para o homem e como única possibilidade de sobrevivência para a mulher na ausência do pai:

\begin{abstract}
e no décimo mês o pai morreu em seus braços, deixando-a [Caroline Beaufort] transformada em órfã e mendiga. Vencida por este último golpe, estava ajoelhada junto ao caixão de Beaufort chorando amargamente, quando meu pai entrou na sala. Foi como um espírito protetor para a pobre moça, que se entregou aos seus cuidados; após o enterro do amigo, levou-a para Genebra e entregou-a a pessoas de confiança. Dois anos após esse evento, Caroline tornou-se sua esposa. Havia uma diferença de idade considerável entre meus pais, mas isso parecia apenas uni-los ainda mais com os laços de uma devota afeição (SHELLEY, 2011, p. 40).
\end{abstract}

Também, observamos a representação da dependência, beleza e fragilidade da mulher da época: "Ele se empenhava em protegê-la, como um jardineiro protege uma bela planta exótica de qualquer vento mais forte, e em cercá-la com tudo o que despertasse emoções agradáveis em seu coração bondoso e delicado" (SHELLEY, 2001, p. 41). Outrossim, notamos questões referentes à classe e raça, tais como, reproduções do discurso da pureza racial, valorização do europeu, como no momento que Walton descreve Victor: "Ele não era, porém, como o outro viajante dera a impressão de ser, um habitante selvagem de alguma ilha desconhecida, mas sim um europeu" (SHELLEY, 2001, p. 31).

Diante disso, podemos dizer que Mary Shelley, em sua "medonha criação", atém-se aos fatos de forma verdadeira, como assente Woolf (1985) nesse respeito? Lembrando que "quanto mais verdadeiros os fatos, melhor a ficção" (WOOLF, 1985, p. 22). Ou estava rendendo "homenagem à convenção" (Ibid., p. 64), segundo as ideias de Woolf? Não poderíamos dizer que Shelley, em Frankenstein, também estaria escrevendo um romance com uma pitada histórica, uma vez que ele se passa no século XVIII, evocando a história? Como vemos neste fragmento: “As margens do Tâmisa apresentavam-me uma nova paisagem; [...] quase todas as cidades estavam marcadas pelas recordações de alguma história. Vimos o forte Tilbury e nos lembramos da 'Invencível Armada' ${ }^{31} ;[$...] e a Torre famosa na história inglesa" (SHELLEY, 2011, p. 173, grifo da autora).

Woolf (1985, p. 128) termina seu ensaio dizendo que o seu propósito não era comparar os dois sexos, mesmo como escritores, mas "saber quanto dinheiro as mulheres tiveram, e quantos quartos, do que teorizar sobre sua capacidade”. Ademais, tudo que mencionou, como a questão do equilíbrio na mente para expressar-se com integridade, o autor conseguirá quando

\footnotetext{
${ }^{31}$ Grande esquadra do Rei Filipe II da Espanha que foi devastada por tormentas no percurso inglês com intenção de destronar Elizabeth I em 1588, levando a Espanha a decadência pelo dispêndio (nota nossa).
} 
houver liberdade e paz ao momento da criação (WOOLF, 1985). Por isso, um teto todo seu, com trancas, para se poder pensar por si mesmo, e rendas, para ter o poder de contemplar. Com isso, Woolf (1985, p. 131) deixa explícito que "a liberdade intelectual depende de coisas materiais". Percebemos que Mary Shelley também teve tudo isso, um teto e rendas para sua criação, fruto do seu trabalho como escritora, como fica claro por algumas citações transcritas por nós.

A escolha do tema de Shelley, para seu Frankenstein, por ter um objetivo maior - os "perigos da ciência e da busca desmedida por conhecer o mistério da vida - faz com que sua obra tenha ainda hoje um significado importante, visto que as descobertas da ciência moderna para alongar, mudar ou criar vida evocam as mesmas questões: o que é a vida? O que é o ser humano?" (BRITO, 2017, p. 21).

Ademais, para Naiara Santos (2015, p. 451, grifo da autora), o cinema vem propiciando novas descobertas e releituras por meio da literatura; "o Complexo de Frankenstein ${ }^{32}$, por exemplo, é tema recorrente em grandes produções cinematográficas, visto que ele se fundamenta no medo que o homem tem de perder seu lugar para as máquinas ou na rivalidade existente" entre ambos.

Constatamos que Frankenstein, de Mary Shelley, 200 anos depois de sua publicação, continua presente entre nós, pois "é a leitura que dá sentido ao texto" (REIS, 1992, p. 76), moldado com um tema forte, marcante, surpreendente, que esconde por trás de suas linhas um segredo que intriga a ciência e a tecnologia, desafiando anjos e demônios, uma obra matricial da genialidade feminina.

Neste trabalho, seguimos as sugestões dadas por Woolf, em seu ensaio, mesmo não sendo alunas de uma universidade famosa britânica (para quem ela sugere a missão de evidenciar nem que seja um nome de escritora "não conspícuo" antes do século XVIII), para apresentarmos um nome notável, que nasceu no século XVIII, que, como vimos, figura com "propriedade" no século XIX, pois, Mary Shelley não deve ser percebida, como diz Woolf (1985, p. 58) acerca da mulher, "de relance na vida dos grandes homens", nem tão pouco deixada à margem ou invisibilizada nas prateleiras de um museu.

Se por um lado, Shelley viveu em uma sociedade patriarcal do século XIX vitoriana, na qual a mulher deveria ser submissa ao homem, por outro, ela viveu condições adequadas à produção ativa feminina. Isso, de certo modo, foi um elemento de significação, já que Shelley nasceu em uma família de pais reformistas, e escritores, gerando um ambiente propício à

32 "Termo utilizado por Isaac Asimov na década de 1950 para designar o medo que os homens têm de serem substituídos ou destruídos por robôs” (SANTOS, 2015, p. 451, nota da autora). 
formação de uma mulher em condições de escrever seu nome na história literária, com livros que deveriam estar incandescentes nas estantes do Museu Britânico.

Contudo, acreditamos que o fato de Mary Shelley não compor a lista de Virginia Woolf só reitera a ideia de que Shelley escreveu além da escrita de autoria feminina de seu tempo, desafiando os valores canônicos defendidos por Woolf, uma vez que o escrito desta corrobora, exatamente, com o discurso vigente da época, um discurso reducionista, que está muito aquém de Mary Shelley, uma mulher muito além do seu tempo, com ideias que permanecem, até hoje, influenciando às artes ao redor do mundo.

\section{Referências}

BLOOM, Harold. O cânone ocidental: os livros e a escola do tempo. Trad. Marcos Santarrita. Rio de Janeiro: Objetiva, 1994.

BRITO, Márcia Xavier de. Introdução. In: Frankenstein ou o Prometeu moderno. Trad. Márcia Xavier de Brito; Carlos Primati. Rio de Janeiro: Darkside Books, 2017. p. 15-21

BURGESS, Anthony. A Literatura inglesa. Trad. Duda Machado. 2. ed. São Paulo: Ática, 2002.

COSTA, Sílvia M. F. A. da S. A dádiva: dar, receber e retribuir em Orgulho e Preconceito e Norte e Sul. In: ARANHA, Marize; ARAÚJO, Naiara; ALMEIDA, Sonia (Orgs.). Discursos linguísticos e literários: investigações em Letras. São Luís: EDUFMA, 2017. p. 173-192.

DIOGO, Rita de Cassia. Borges e Bloom frente ao cânone literário: um diálogo. In: Congresso Brasileiro de Professores de Espanhol, 7, 1999, Belo Horizonte. Panorama Hispânico. Belo Horizonte: APEMG, 1999. v. 1, p. 318-325.

ELLIOT, T. S. Ensaios. Trad. Ivan Junqueira. São Paulo: Art, 1989.

FELDMAN, Paula R. Introduction to a re-edition of The Keepsake for 1829. In: REYNOLDS, F. M. (Ed.). The Keepsake for 1829. [S.1.]: Broadview Press, 2006. p. 7-25.

GASKELL, Elizabeth. Norte e Sul - North and South. Trad. Doris Goettems. São Paulo: Landmark, 2011.

LOVECRAFT, H. P. O horror sobrenatural em literatura. Trad. Celso M. Paciornik. São Paulo: Iluminuras, 2012.

PAES, José P. Gregos e baianos. São Paulo: Brasiliense, 1985.

PRIMATI, Carlos. Introdução aos contos. .In: SHELLEY, Mary. Frankenstein ou o Prometeu moderno. Trad. Márcia Xavier de Brito; Carlos Primati. Rio de Janeiro: Darkside Books, 2017. p. 238-242. 
REIS, Roberto. Cânon. In: JOBIM, José Luís (Orgs.). Palavras da crítica. Rio de Janeiro: Imago, 1992.

SANTOS, Naiara Sales A. Frankenstein e a arte de recriar. In: EUGÊNIO, João K.; TORRES, Wanderson L. (Orgs.). Cinema e mal-estar na civilização. São Paulo: Max Limonad, 2015. p. 451-461.

SHELLEY, Mary. Frankenstein ou o Prometeu moderno. Trad. Adriana Lisboa. Rio de Janeiro: Nova Fronteira, 2011.

Frankenstein ou o Prometeu moderno. Trad. Márcia Xavier de Brito; Carlos Primati. Rio de Janeiro: Darkside Books, 2017.

SHELLEY, M.; BRAM, S.; STEVENSON, R. L. Frankenstein, Drácula e O médico e o monstro. Trad. Adriana Lisboa. Prefácio de Stephen King. Rio de Janeiro: Ediouro, 2001.

SILVA, Alexander Meireles da. Literatura Inglesa para Brasileiros. 2. ed. Rio de Janeiro: Ciência Moderna, 2006.

WOOLF, Virginia. Um teto todo seu. Trad. Vera Ribeiro. São Paulo: Círculo do Livro, 1985.

ZOLIN, Lúcia O. Crítica feminista. In: BONNICI, T.; ZOLIN, L. Osana (Orgs.). Teoria Literária: abordagens históricas e tendências contemporâneas. 3. ed. Maringá: Eduem, 2009. p. 217-242.

Recebido em 25/08/2018 